\title{
Responsibility for Climate Change as a Structural Injustice
}

\author{
Robyn Eckersley
}

University of Melbourne

In Oxford Handbook of Environmental Political Theory, edited by Teena Gabrielson, Cheryl Hall, John M. Meyer and David Schlosberg (Oxford: Oxford University Press, 2016), pp. 346-361.

\begin{abstract}
This chapter critically explores the political and moral challenges involved in understanding the harms of climate change as the product of structural injustices with a specific focus on political responsibility. The chapter stages a critical encounter between Iris Marion Young's account of political responsibility, on the one hand, and the debate among climate justice theorists on how to assign responsibility for mitigation and adaptation to citizens and states, on the other. This encounter demonstrates the value of a hybrid approach that includes, and bridges, forward and backward looking responsibility, but also reveals a major predicament. The more that structural injustices based on historical responsibility are backgrounded, the easier it becomes to reach agreements between the world's most vulnerable and most privileged. Yet, doing so accelerates the skewed distribution of climate vulnerability towards the least privileged diminishing the common ground needed to achieve an equitable allocation of responsibility for climate change.
\end{abstract}

\section{Key words}

Responsibility, structural injustice, liability, Iris Marion Young, climate justice, polluter pays principle, beneficiary pays principle, ability to pay principle 


\section{Introduction}

Environmental protection is generally accepted as a public good, and the task of preventing environmental degradation is widely understood as a collective responsibility. But there is much disagreement about how this responsibility is to be shared among states, corporations and citizens in a globalising world. Indeed, the increasing integration of the global economy through the processes of liberalisation has, paradoxically, challenged the conventional liberal grammar of responsibility, which is rooted in notions of individual agency, direct causation and culpability.

How we frame problems, and how we think about the relationship between agents and structures, shapes how we think about responsibility. The dominant frame for thinking about environmental problems comes from economics: such problems are 'negative externalities', which are the unintended and unwanted side-effects of normal practices of production and consumption. This framing serves to naturalise the practice of privatising gains and socialising losses and thereby absolves economic agents of responsibility until such time as regulators step in or 'third party' victims turn to litigation.

The purpose of this chapter is explore what is gained, and what might be lost, if the harmful impacts of climate change are understood as the product of structural injustices, and whether this necessarily requires a forward looking rather than backward looking understanding of responsibility. In posing the problem this way I critically engage with Iris Marion Young's reflections on responsibility in her posthumously published book Responsibility for Justice (2011). ${ }^{\mathrm{i}}$ Unlike individual injustices, where undeserved harms can be traced to the wilful or negligent acts of identifiable 'culprits', structural injustices are undeserved harms that are collectively produced through recurrent social practices that are considered 'normal' and therefore non-blameworthy. To address this particular type of 
injustice, Young argued that it is necessary to avoid a backward looking, 'liability model' of responsibility that focuses on blaming particular culprits. Instead, she defended a more critical, forward-looking account of shared responsibility based on accountability, grounded in her 'social connection' model, according to which all those who participate in the social structures that systematically produce undeserved harm bear responsibility for challenging, debating and transforming those structures to reduce such harm.

Although Young's primary focus was poverty, and the particular problem of sweatshop labour in developing countries, her arguments can be readily applied to climate change. Here the primary injustice is that many of the world's poorest and least developed communities will suffer the worst impacts of climate change despite making the least contribution to the problem. At the same time, their marginal social structural position in the economy and the state system not only exposes them to most of the risks, and few of the benefits, generated by these social structures but also places them in a particularly weak position to orchestrate their transformation in ways that will reduce vulnerability.

Of course, Young is not the only political theorist to reflect on responsibility or structural injustices. Both have been major themes in environmental political theory (EPT) and there is a rich literature within EPT and cognate fields that specifically focuses on assigning responsibility for mitigation and adaptation to states, individuals and other actors (e.g. Caney 2005, 2010; Vanderheiden 2008, 2011; Gardiner 2011; Page 2012). There is also a mounting environmental critique of the limitations of existing practices of corporate responsibility, and more general accountability practices in governance, alongside growing interest in new norms of responsibility in public and private governance and environmental citizenship (Dobson 2003), all of which seek to cater for the distinctive nature of transboundary environmental harm (e.g., Mason 2008). And environmental justice scholars have shown that the skewed distribution of environmental risks and harms reflects not simply 
a structural problem of distributive justice but also a lack of social recognition of, and political participation by, the affected groups (Schlosberg 1999 and 2007). However, it is probably Ulrich Beck's critique of 'organised irresponsibility', which forms a key plank in his theory of the risk society (e.g., Beck, 1995), that most resonates with Young's structural analysis. Despite these strong overlaps, her arguments are distinctive in at least two interesting respects.

First, whereas most of the climate ethics debates have focused on moral responsibility, Young is primarily interested in clarifying the special character of political responsibility for structural injustices. Of course, political responsibility cannot be dissociated from moral responsibility, and this essay will certainly highlight these connections. Yet not all forms of moral responsibility necessarily relate to structural injustices, or have a political character in the sense that they involve a public. Young's contribution is to sharpen our thinking about responsibility so that we are better equipped to reflect, communicate and act politically in pursuit of the public good of environmental protection, which may therefore be understood as a 'structural justice'.

Second, Young's critique of the backward-looking, liability model of responsibility poses a potential challenge to the arguments mounted by many developing countries and climate justice activists for the historical responsibility of developed countries for their cumulative emissions since the beginning of industrialisation. A considered reply to this challenge holds the promise of revisiting with fresh eyes the long-standing stalemate between developed and developing countries over this vexed issue.

The discussion that follows is organised around these two distinctive features of Young's account. I begin by outlining in a little more detail Young's critique of the liability model and her alternative account of the political responsibility of citizens for structural injustices. Next I focus on the daunting character of this responsibility for citizens in relation 
to climate change, and offer some refinements of Young's analysis of the relationship between power and responsibility. I then move from citizens to states by providing a critical exploration of the implications of her critique of the liability model to arguments for the historical responsibility of states for climate change. In the conclusion, I connect Young's thinking on political responsibility to the sociological literature on risk and responsibility and draw out some of the unavoidable political and moral tensions that emerge from the analysis.

\section{The liability model}

In the English language, 'responsibility' is one of those especially over-burdened words. Being responsible can mean any of the following: simply causing an outcome; being culpable and therefore morally blameworthy for an outcome; being legally liable for an outcome; being accountable or answerable for a problem; having certain duties associated with professional roles or capabilities, or arising from the membership of a particular community; or being obligated, or volunteering, to get a job done. Cutting across these different meanings are various categories of responsibility - moral, legal (strict or faultbased), professional and political.

Young's critique of the 'liability model' of responsibility takes aim at conventional (liberal) moral and legal accounts of responsibility that combine causal responsibility, culpability and the associated obligation to provide redress. This is a powerful and appealing understanding of responsibility that is reflected in conventional moral intuitions as well as the criminal law, the law of torts and international public law, including the principle of state responsibility for environmental harm. This liability model evolved to handle cases involving a relatively clear chain of causation between the harm suffered by identifiable victims and the actions or inactions of identifiable wrongdoers (which may include individuals, incorporated organisations or states) who can be found to have breached a moral principle or duty of care. However, for Young, this model of responsibility is not only unable 
to address structural injustices generated by the activities of literally billions of individuals and organisations engaged in cooperation and competition; it also works actively to obscure the structural character of injustices in ways that make it hard to achieve collective action.

Young fleshes out this central claim with a set of interrelated arguments. First, she maintains that the liability model is politically unproductive because it is isolating, and focuses only the immediate or proximate causes of discrete harms. Moreover, the act of singling out culpable individuals has the effect of absolving everyone else (Young 2011, 105106). ${ }^{\text {ii }}$

Second, the liability model judges wrongfulness on the basis of existing rules and institutions, yet it is precisely many of these rules and institutions that need to be called into question insofar as they legitimate the systemic production of injustices. The liability model therefore plays an ideological role in naturalising existing social structures, thereby foreclosing critical reflection on the very practices that reproduce such structures and preventing the kinds of reforms that are required to prevent structural injustices.

Third, the liability model is backward looking in focusing on fact-finding and faultfinding in relation to past events. In contrast, addressing structural injustices requires a forward-looking approach that challenges and seeks to transform the social practices that continue to produce harm in the present and future.

Finally, Young argues that the search for blameworthy agents tends to produce a highly defensive response from those who are accused of acting wrongly, which deflects attention away from the hard work that needs to be done by everyone to transform social structures.

Young's critique is part of a growing chorus of attempts in EPT and cognate fields to move beyond the liability model of responsibility towards a more critical understanding of responsibility that is appropriate to a global risk society. These arguments are forcefully made 
by Ulrich Beck, who laments how systems of organised irresponsibility have locked in a cynical fatalism over an increasingly 'self-endangering society’ (Beck 1995, 64-65).

Likewise, Chad Lavin (2008) calls for a post-liberal account of responsibility while Andrew Linklater defends an understanding of 'complex responsibility' that entails critically reflecting on the ways in which personal conduct, existing norms and social institutions inflict undeserved harm on distant others (Linkater 2011, 101-102). But how is this broader notion of responsibility to be shared and discharged in relation to the structural injustices of climate related harm?

\section{Political responsibility}

Since globalisation has made political borders more porous, Young argues that political responsibility for structural injustices arises 'not from living under a common constitution, but rather from participating in the diverse institutional processes that produce structural injustice' (Young 2011, 105). This includes participating in transnational economic exchanges. As she explains:

The social connection model of responsibility says that individuals bear responsibility for structural injustice because they contribute by their actions to the processes that produce unjust outcomes. Our responsibility derives from belonging together with others in a system of interdependent processes of cooperation and competition through which we seek benefits and aim to realize projects...All who dwell within the structures must take responsibility for remedying injustices they cause, though none is specifically liable for the harm in a legal sense' (Young 2011, 105).

For Young, political responsibility is not about heroism or charity. Rather, it requires a particular kind of solidarity that must be forged between individuals who may have little in common but for a preparedness to engage in a public debate and collective action for the sake of preventing structural injustices $(2011,120)$. This account returns to the Latin root of the 
word responsibility, respondeo (to answer), and to the French répondre (as in RSVP) (Lucas 1995, 5). Indeed, for J.R. Lucas, 'the central core of the concept of responsibility is that I can be asked the question "Why did you do it?" and be obliged to give an answer' $(1995,5)$.

In the case of climate change, this question can also take the form 'Why did you not do anything?' This is a question that older generations must answer younger generations, rich countries must answer poor countries and everyone must answer those who speak on behalf of nonhuman others. Clearly, political responsibility is not just about answering questions but also asking them. Indeed, responsibility qua answerability does not arise if questions are not asked. Exercising political responsibility for structural injustices such as climate change is necessarily public spirited or other-regarding in the sense that it acknowledges and honours social connection to others through the very practice of asking and answering others in ways that address collective practices, meanings and collective consequences. Conversely, failing to ask or anticipate questions, ignoring or resisting questions, or answering them untruthfully or disingenuously, is tantamount to failing to recognise others by denying one's social connection to others. This understanding of responsibility is grounded in a relational ontology of the self, which draws inspiration from Derrida and Levinas, among others. From Derrida, Young accepts that answering to the other is more originary than answering to one's self, since relations to others are prior to the self (Young 2011, 121). And from Levinas, Young acknowledges that we experience responsibility most primordially in embodied encounters with others, but that these proximate and singular encounters enable us to realise the singularity and equivalence of all other potential encounters with others, and that both are necessary dimensions of responsibility $(2011,162-163)$. Although Young seeks to replace 'blame' with the less loaded notion of 'accountability', this is a rather subtle distinction since it does not signal any shyness about criticism. Political responsibility necessarily presupposes 
a questioning and judging public so we can expect to see shaming and censure by those who raise questions, and discomfort and embarrassment of those who are called to account.

Young's account of political responsibility is primarily directed towards citizens rather than states. While she acknowledges that states have a crucial role to play in transforming structural injustices they do not act as neutral arbiters over the struggle between the interests that produce structural injustices and those who are most disadvantaged by them. Rather, whether such claims will be accepted by key decision-makers will largely turn on the outcome of struggles in the public sphere (Young 2011, 151). Whether, and how, citizens exercise political responsibility for the structural injustice of climate related harm is therefore crucial in shaping the responsibilities of states. I shall therefore address the challenges facing citizens before turning to the vexed question of state responsibility.

\section{Citizens: The vertigo of political responsibility}

Young's particular account of political responsibility, which goes well beyond being a law abiding citizen and exercising one's right to vote, might strike many as overwhelming. Indeed, many might find it paralysing, given the enormity of the task of weaning the global economy off fossil fuel consumption and other emissions generating activities and the fact that climate related harm is only one of many structural injustices in a globalised world. How should we negotiate this 'vertigo of political responsibility' (Young 2011, 124), given our multiple social connections and multiple and competing responsibilities?

In a sympathetic critique of Young, Jacob Schiff has reflected on the difficulties of exercising political responsibility for structural injustices that are woven into the fabric of our everyday lives (Schiff 2008, 106). He notes that such responsibility may be experienced as so 'agonizing and infinite' as to demand a degree of bad faith and the concealment of inconvenient truths from oneself as a form of insulation from the overwhelming burdens of existence (Schiff 2008,108 ). If so, then the exercise of political responsibility for climate 
change is also likely to be exceptional, and most people will outsource political responsibility for climate change to their political representatives, disengage and retreat from the problem or simply deny it. However, as Schiff points out, lying to oneself presupposes that we know the truth of the problem and allow ourselves to forget or conceal it so that we can act against what we know to be right (p. 108). Yet there are also many people who do not recognise the problem, or rather misrecognise it, because they are ensnared in the dominant practices and associated categories of thought and perception embodied in language, which reinforce the legitimacy of prevailing social structures.

Given these challenges, what should we expect of citizens and how are they to be judged? Young acknowledges the unavoidable tensions we all face between the responsibilities that arise from interactions with others in close proximity (such as family and friends) and the responsibilities that arise from participation in social structures. Indeed, she argues that to acknowledge this tension is to acknowledge that 'it is impossible to say that we ever discharge our responsibilities' (p. 163). This probably explains her interest in developing 'rhetorics of responsibility that are specifically political and that have fewer echoes of moralistic or juridical language' than the liability model $(2011,118)$. Nonetheless, she argues that the more that privileged groups attend to their immediate responsibilities, the more they will reinforce structural injustices by virtue of their structural position $(2011,164)$. Young's defence of the virtues of public-spirited political questioning and engagement shares and builds upon Hannah Arendt's critique of the passive politics of privatised, bourgeois life that avoids civic engagement and elevates personal and/or family security and prosperity above all else, whatever the cost to others.

Turning specifically to political responsibility, Young insists that this responsibility must be shared while also accepting that not everyone can be expected to exercise the same kind or degree of political responsibility (Young 2011, 143-144). To develop this claim, 
Young sketches some broad 'parameters of reasoning' for guiding reflection on how differently situated actors might exercise political responsibility to address structural injustices based on how much power or privilege they may have, what their interests are and whether they have 'collective ability' (Young 2011, 142-151). For Young, power in this context is understood to mean the ability to influence the social structural interactions that produce unjust outcomes. That is, each actor's abilities or capabilities are largely (though not exclusively) derived from their social structural position. Social structures position people in particular relationships, which shape their capabilities and the range and kinds of options available to them, generating positions of relative privilege and under-privilege. For example, owners of capital are in a better position to make decisions to invest in renewable energy research, development and production, or divest from the fossil fuel industry, than wage labourers or the unemployed. In contrast, the degree of 'collective ability' refers to whether actors are part of organisations with a large membership (such as unions, nongovernment civic or religious organisations), which have much greater potential for collective action than individuals who act alone or in smaller groups $(2011,146-151)$. In short, we should exercise our political responsibility by using our membership of organisations, our roles in the workforce and society, and whatever other capabilities we have as citizens and consumers, to drive the necessary structural transformation to a low carbon, sustainable society.

However, as Young acknowledges (building on the heritage of Karl Marx), one of the key challenges is that there is typically an inverse relationship between power and privilege, on the one hand, and the interest to transform social structures, on the other. Those who are the major beneficiaries of such processes have the greatest power to transform them but typically have little interest in doing so, and vice versa. This is starkly illustrated in the case of climate change, where the executives, workers and states that are highly dependent on 
fossil fuel extraction and consumption remain mostly in denial of their complicity in hastening the possibility of catastrophic climate change, and remain largely deaf to the pleas of the most climate vulnerable, such as communities in low-lying nations and coastal areas. In response, Young suggests that the most vulnerable and marginalised can seek the support and assistance of others with greater power and privilege, but with less of an interest in perpetuating structural injustices, to mobilise on their behalf. Young also notes that many organisations and corporations may come to see their longer-term interests as aligned with transformation. In the case of climate change, this might include insurance companies, banks, pension funds, and other investors concerned about the possibility of holding stranded assets, along with a wide range of businesses that stand to gain from decarbonisation or suffer from a failure to decarbonise.

\section{Power and Responsibility}

Young's parameters of reasoning provide a useful first cut in thinking about how citizens might discharge their political responsibility. However, they contain some tensions and also raise further questions regarding the applicability of her arguments to states and other actors.

First, the tensions. Young's social connection model assumes that citizens are rational and autonomous agents, capable of recognising universal moral principles, making and executing moral political choices, asking questions in the public sphere and exerting influence on social structures. However, her constructivist sociology acknowledges that citizens often bear little resemblance to the unencumbered, freely choosing individual of liberal moral theory (Hoover 2012, 237), since they are unavoidably ensnared in social structures (most notably, the relations of exchange in a neoliberal, global capitalist economy) and therefore constrained in what they can think, desire and do by their particular social position. Her 'parameters of reasoning' seek to negotiate this tension by acknowledging the 
constraining effects of social structures on individual capability, but this negotiation rests on a rather thin and instrumental account of power as influence (Schiff 2013). Admittedly, Young's focus was confined to the intentional, agential power of citizens to exert influence on social structures. Nonetheless, had she developed a broader understanding of power for this particular purpose, she would have highlighted a greater range of challenges, and opportunities, for social transformation. Young would be the first to concede that power is much more than the relative capacity possessed by differently situated social agents to transform social structures. Power is not only intentional, active and agential; it can also be diffuse, unintended, structural and productive (via discourses), and its effects can arise from doing nothing (e.g., Lukes 2005; Barnett and Duvall 2005).

Although Young does not provide any systematic account of the role of discursive power in legitimising structural injustices, she has sharp antennae for the various strategies employed by privileged agents to evade, avoid and deny responsibility for structural injustices (which typically include 'hiding behind' the liability model). These include: 1) Reification - the pretence that the processes that produced undeserved harm are natural, a matter of bad luck or otherwise inevitable and therefore unavoidable and unchangeable; 2) Denial - the failure to acknowledge any connection between social practices, and the injustices that are suffered by others; and 3) Immediacy - the idea that we only have responsibility to our immediate neighbours or compatriots, not distant others (2011, chapter 6). These are precisely the strategies of evasion and avoidance of responsibility for preventing dangerous climate change employed by many states, political parties, corporations and citizens in developed countries. And they are arguably far more politically potent in stalling effective action on climate change than the more blatant, and often desperate, propaganda strategies of the organised climate denial movement, which has a particularly strong base in English speaking jurisdictions. So how might the forward-looking climate 
responsibilities of the wealthy and the privileged be framed in ways that might serve to galvanise positive action rather a defensive reaction? Replacing liability/guilt with accountability/shame moves the debate from the legal and moral sphere to the political sphere but it depends for its success on those who are publicly criticised sharing a sense of social connection to, and moral concern for, others in order to be swayed to accept responsibility. This can be a tall order.

Second, Young confines her focus to the political responsibilities of citizens on the grounds that states lack the motivation to take responsibility for climate change, and the policies they enact will largely turn on the outcome of struggles in the public sphere. However, public spheres are not confined to the domestic level and the politics of assigning, accepting, claiming, defending or shirking responsibility are also basic to international politics (Bukovansky et al 2012). What, then, are the implications of her critique for framing state responsibilities for climate change?

\section{States: Historical versus political responsibility?}

Young's critique of the liability model of responsibility appears to provide a fundamental challenge to all those wishing to pin historical responsibility on the early industrialisers, as well as to those seeking compensation for 'loss and damage' from the present and future harmful impacts of climate change that are already locked in since industrialisation. An uncritical application of Young's argument would run as follows: we should avoid the fraught process of trying to pin blame and liability on the biggest historical emitters for their past actions because it does not spread responsibility wide enough. It is isolating, backward-looking, deflects attention from shared responsibility, does not challenge existing economic institutions, produces a defensive reaction by those singled out and is politically unproductive. The US, in particular, has been strongly resistant to the liability model and/or the idea of historical responsibility as a basis for burden sharing, and has argued 
that we must look forward and not backward by focussing on the regions of the world where the biggest future growth in emissions is expected. For their part, major emitters in the developing world, such as China and India, have avoided stringent international commitments until such time as major developed countries such as the US accept historical responsibility. According to Young's line of argument, a new regime of responsibility for climate change would need to acknowledge shared responsibility of all states in order to prevent exactly this kind of stand-off. Yet it would also need to recognise that responsibility needs to be calibrated in accordance with each state's different capabilities derived largely (but not exclusively) from their social structural position in the society of states and the global capitalist system. In other words, political responsibility for mitigation should be aligned with the relevant capabilities of states to prevent future emissions growth, which means that the primary focus for mitigation should be on all major emitters in order 'to get the job done'.

Translated into the language of climatic ethicists, Young's arguments align with the forward-looking Ability to Pay Principle (APP) rather than the backward looking Polluter Pays Principle (PPP). The latter has attracted a range of objections, the most significant of which are the defence of excusable ignorance by the polluter, the challenge of measurement, the fact that most past individual polluters are now dead (although many states and corporations endure) and that the PPP leaves unaddressed climate related harms that cannot be attributed to the polluter (e.g., Vanderheiden 2008, 2011; Caney 2010; Meyer and Roser 2010; Gardiner 2011; Page 2012).

Yet these objections have been met with a range of considered replies, including modified versions of the PPP, the defence of the Beneficiary Pays Principle (BPP) and/or the development of hybrid models that include elements of the PPP, APP and BPP (discussed further below). It is beyond the scope of this chapter to rehearse these arguments in detail but 
the key point for present purposes is that most of these climate justice debates have been confined to the morality rather than politics of assigning responsibility. One of the few exceptions is Pickering and Barry (2012), who assess both the moral and political value of framing the climate responsibilities of developed states in terms of a climate or carbon debt based on their historical contribution. While they concede that it is possible to develop a coherent moral account of historical responsibility, they nonetheless conclude that it provides a politically unhelpful frame in the climate negotiations for reasons that are consistent with Young's: it poses the risk of overemphasizing retrospective liability at the expense of future distributive concerns, its adversarial nature and the problems associated with measurement. Indeed, they suggest that 'many developing countries (including highly vulnerable small island states) have themselves eschewed the rhetoric of climate debt in favour of other strategies for boosting collective responsibilities to address climate change' (p. 679). Drawing on John Dryzek's distinction between bonding rhetoric (which preaches to, and seeks to mobilise, the already converted) and bridging rhetoric (which seeks to reach across polarised divisions and find common ground), they argue that historical responsibility constitutes a form of bonding rhetoric that is inflammatory to many developed countries (especially the US) and unlikely to advance the negotiations (p. 679). Bridging rhetoric (such as collective responsibility) is therefore to be preferred since it is more likely to facilitate deliberation and compromise.

Given the diminishing window of opportunity to reach a fair and effective agreement, these arguments certainly have practical political merit. But it also needs to be asked: what are the political consequences of rejecting historical responsibility based on the PPP? A complete rejection of the liability model or the PPP seems unduly lopsided and ahistorical in the case of climate related harms: it wrongly assumes that responsibility qua liability and responsibility qua accountability are mutually exclusive and fails to acknowledge how 
present capabilities are historically derived and connected to present structural injustices. An outright rejection of the liability model could also be seen as justifying a politics of appeasement that serves to uphold the status quo advantages of the major cumulative emitters, thereby providing little comfort to late developers but especially those who are the most vulnerable to climate change and also the least responsible for generating emissions. This is no less politically unproductive from the standpoint of many late developers as an uncritical application of the liability model of responsibility since it plays into the hands of the most advantaged at the expense of the most disadvantaged.

However, Young's analysis of historical responsibility for slavery suggests that she too would probably reject such an uncritical application of her arguments. First, she accepts that liability and political responsibility can co-exist. ${ }^{\text {iii }}$ Second, although she rejects the case for reparations for the historical injustice of slavery when the perpetrators and victims are long dead, she nonetheless argues that unrepaired past injustices create a present political responsibility to deal with unfinished business $(2011,176-179)$. That is, ensuring public recognition of the continuities between present structural injustices and the past practices that produced them provides added weight to the political case for the transformation of present racialised structures. She also argues that those who are the beneficiaries of racialised structures 'can properly be called to a special moral and political responsibility' to recognise their privilege and its connection with past wrongful practices and to work towards changing present structures, even if it entails reducing their own privileges and opportunities (2011, 187).

Likewise, it matters how state capabilities are derived. Those states that have economically benefited from a longer history of emissions should have a greater responsibility to mitigate and to provide finance for mitigation and adaptation for less developed countries, and this can be achieved under the BPP without attaching the 'blame' 
associated with the PPP, qua liability model. As Edward Page has explained, the BPP is distinguishable from the PPP insofar as it entails 'giving up' rather than 'paying back' a benefit unwittingly but unjustly acquired (Page 2012, 314). Indeed, a refusal by developed countries to 'disgorge their fair share of climatic benefits for the sake of the global climate response would put states in the position of condoning the setbacks of interest to which their affluence can be historically linked' $(2012,315)$.

Those critical theorists who have placed structural injustice to the front and centre of their analysis of climate change have highlighted the structural links between the past and present skewed distribution of benefits and burdens in the international economy. A notable example is Parks and Roberts (2010), who locate the structural injustice of climate change in the context of the more general unequal flows of energy, resources, materials between the North and the South arising from the colonial legacy and the shifting division of labour in an increasingly integrated global economy. It is this unequal load displacement or 'unequal ecological exchange' that underpins the claim that the North owes an ecological debt to the South on the grounds that it has used an excessive proportion of 'ecological space' at the expense of the South. The carbon debt is merely one component of this larger ecological debt and it arises not just from the colonial legacy but from the constantly shifting international division of labour. That is, participation in international trade tends to decrease emissions in many wealthy countries, which have increasingly specialised in the service sector, while increasing them in developing countries where heavy industry has become increasingly concentrated. This enables citizens in developed countries to enjoy the benefits of carbon intensive good imported from, say China, without having to accept responsibility for the emissions associated with their production. Yet this unequal ecological exchange can flow in different directions, depending on how different local and national economies are 'inserted' into the global economy, but either way it escapes the territorial and production-based 
accounting system of the climate regime.

While the BPP provides a useful principle to 'catch' early industrialisers and carbon free riders through emissions offshoring, the virtues of Young's social connection model would appear to provide strong grounds for the responsibility of the wealthy to transform international economic structures to address the skewed distribution of benefits and burdens produced by international exchanges irrespective of any direct link between their enjoyment of the climate related benefits and the burdens suffered by others, simply by virtue of participation in international economic exchange. As Simon Caney $(2010,212)$ has shown, no single principle can frame responsibility in ways that provide comprehensive justice for the most vulnerable. And this is becoming increasingly apparent in the global risk society (see also Bukovansky et al 2012, chapter 4). The PPP leaves unaddressed climate-related harms that cannot be attributed to particular polluters; the BPP is limited by the degree to which the beneficiary actually benefited from unwittingly causing a harm (which may not be sufficient to cover the loss suffered by, or assistance required, by the victim); and the APP cannot discriminate between the innocent and the culpable among the wealthy, or the 'clean' and 'dirty' rich. That said, the BPP provides a helpful ethical and political bridge between the forward-looking responsibility to mitigate (a matter of distributive justice), and the backward looking responsibility to assist and compensate (a matter of compensatory or remedial justice) (Vanderheiden 2011; Meyer and Roser 2010). Indeed, as Miller points out, this kind of remedial responsibility can be both backward and forward looking (Miller 2008, 99-104).

None of the above arguments should rule out the application of the liability model in cases where states (or indeed corporations) continue to produce significant emissions in full knowledge of the consequences for the most vulnerable states and communities. While a strict version of the PPP from the beginning of industrialisation is too punitive, given that the earlier industrialisers did not know that their emissions generating activity would cause harm, 
a culpability/liability based responsibility can be invoked from the time when the science of climate change became widely known and a matter of international concern, such as from the beginning of the negotiations for a climate change treaty in the late 1980s.

\section{Conclusion}

Young's reflections on political responsibility for structural injustices are a response to profound shifts in the social relations of risk and responsibility. Her reflections highlight the different ways in which the liability model is unable to deal with growing interdependence and increasingly complex, incalculable and uninsurable character of risks generated by the social structures of the (neoliberal) risk society (Voigt 2008). Her social connection model pushes in the direction of a new understanding and practice of 'extended responsibility' that move beyond the interests of contractual parties and principal-agent models of responsibility, and the language of 'negative externalities', to embrace a broader and a more risk-averse guardianship or trusteeship model of responsibility that acknowledges pervasive and complex social and ecological interconnectedness (Christoff and Eckersley 2013, 190-193).

Two broader insights emerge from the foregoing discussion. The first is that while we need a post-liberal understanding of environmental responsibility to adapt to a more complex, interdependent world, this does not mean that the traditional liberal understanding of responsibility should be obliterated. The liability model still has an important role to play in providing corrective justice to the vulnerable for so long as structural injustices persist and the necessary connections between culpability and harm can be drawn but there is no motivation on the part of the powerful to transform social practices. Indeed, as Anthony Langlois has shown, in the anti-sweatshop campaigns examined by Young it was, ironically, the application of the liability model rather than the exercise of political responsibility by corporations that largely explains the positive changes in corporate practices (Langlois 2014: 
56-59). More generally, a hybrid model that includes elements of the PPP, BPP and APP is most likely to produce an agreement that will serve the needs and interests of differently situated states and other social actors, including the most vulnerable.

Second, bringing structural injustices into the foreground of responsibility, especially when based on PPP or even the BPP, is politically confronting. Conversely, allowing these principles to recede into the background of political negotiations is likely to remove obstacles to agreement about the allocation of responsibility from the standpoint of those social actors that have derived their privilege from past and/or present existing social structures. But this produces a major predicament or Catch-22: this backgrounding leaves intact social structures that can be expected to generate a further widening of the gulf between those who enjoy the benefits and those who suffer the burdens produced in the global risk society, and this will further strip the capability of the already vulnerable to shape their destiny while also making it harder to reach any common ground with the most privileged. As Parks and Roberts (2010) have argued, deep disagreement about the allocation of responsibilities in the international climate negotiations is a predictable outcome of a starkly unequal world, which has produced different understandings of fairness, causation and responsibility between (and increasingly within) the North and South. Indeed, the same can be said for the negotiation of national climate policy. In short, unchecked inequality undermines trust and cooperation. It follows that if trust is to be built and cooperation over climate change enhanced, then inequality must be addressed. In the international sphere, Parks and Roberts suggest broadening the negotiation agenda to include issues such as trade, investment, debt and intellectual property rights (p. 136). However, this brings us back to our dilemma: if some kind of new international economic deal were to serve as precondition for a new climate deal by developing countries, then we can expect the stalemate to deepen, to the detriment of the most marginal and disempowered given the diminishing window of opportunity to produce a 
fair and effective agreement. Indeed, even without this expanded agenda, the negotiations leading to the scheduled 2015 climate agreement have all but given up on reaching agreement on the equitable allocation of responsibilities by leaving it to individual states to put forward their own 'nationally determined contributions' on the basis of their own understanding of equity.

Against this background, it is fitting to return to the political responsibility of nonstate actors, especially citizens, to provide the necessary motivation and political mobilisation for states to negotiate a fair and ambitious agreement. In bringing social connections to the foreground of public engagement Young's reflections direct attention to the tight links between the ideals and practices of political responsibility, public accountability and deliberative democracy. Political responsibility means asking critical questions, and being answerable to others in the sense of revealing, explaining and justifying what one has done (and not done), what one wishes to get done by way of collective action, and doing so publicly. Herein lies the surest path away from 'organised irresponsibility' and the awful prospect of catastrophic climate change.

\section{References}

Barnett, Michael and Raymond Duvall. 2005. 'Power in International Politics', International Organization 59: 39-75.

Beck, Ulrich. 1995. Ecological Politics in an Age of Risk (trans. By Amoz Weisz). Cambridge: Polity Press. 
Bukovansky, Mlada., Ian Clark, Robyn Eckersley, Richard Price, Christian Reus-Smit and Nicholas J. Wheeler, N.J., 2012. Special Responsibilities: Global Problems and American Power (Cambridge: Cambridge University Press).

Caney, Simon. 2005. 'Cosmopolitan Justice, Responsibility, and Global Climate Change', Leiden Journal of International Law 18: 747-775.

Caney, Simon. 2010. 'Climate change and the duties of the advantaged', Critical Review of International Social and Political Philosophy 13 (1), 203-228.

Christoff, Peter and Robyn Eckersley. 2013. Globalization and the Environment. Lanham: Rowman and Littlefield.

Dobson, Andrew. Citizenship and the Environment. Oxford: Oxford University Press, 2003.

Gardiner, Stephen. 2011. A Perfect Moral Storm: The Ethical Tragedy of Climate Change. Oxford: Oxford University Press.

Guzzini, Stefano. 2005. 'The Concept of Power: A Constructivist Analysis', Millennium 33(3): 495-521.

Hoover, Joseph. 2012. 'Reconstructing Responsibility and Moral Agency in World Politics', International Theory 4(2): 233-268. 
Langlois, Anthony. 2014. 'Social Connection and Political Responsibility: An Engagement with Iris Marion Young', St Antony's International Review 10(1): 43-63.

Lavin, Chad. 2008. The Politics of Responsibility. Urbana and Chicago: University of Illinois Press.

Linklater, Andrew. 2011. The Problem of Harm in World Politics: Theoretical Investigations. Cambridge: Cambridge University Press.

Lucas, J. R. 1995. Responsibility. Oxford: Oxford University Press.

Lukes, Steven. 2005. 'Power and the Battle for Hearts and Minds', Millennium 33(3): 477493.

Mason, Michael. 2008. 'The Governance of Transnational Environmental Harm: Addressing New Modes of Accountability', Global Environmental Politics 8(3): 8-24.

Meyer, Lukas H. and Dominic Roser. 2010. 'Climate Justice and Historical Emissions', Critical Review of International Social and Political Philosophy 13(1): 229-253.

Miller, David. 2007. National Responsibility and Global Justice. Oxford: Oxford University Press.

Page, Edward, 2012. 'Give it up for Climate Change: A Defence of the Beneficiary Pays Principle', International Theory 4 (2): 300-330. 
Parks, Bradley C, and J. Timmons Roberts. 2010. 'Climate Change, Social Theory and Justice', Theory, Culture \& Society 27(2-3): 134-166

Pickering, Jonathan and Christin Barry. 2012. 'On the Concept of Climate Debt: Its Moral and Political Value', Critical Review of International Social and Political Philosophy 15(5): $667-685$.

Schiff, Jacob. 2008. 'Confronting Political Responsibility: The Problem of Acknowledgment Hypatia 23(3): 99-117.

Schiff, J.L. 2013. 'Power and Responsibility' in Political Responsibility Refocused: Thinking Justice after Iris Marion Young, edited by Genevieve Fuji Johnson and Loralea Michaelis (Toronto: University of Toronto Press), 42-62.

Schiff, Jacob. 2009. 'Power and Responsibility: A reconsideration', Paper prepared for the Annual Meeting of the Canadian Political Science Association, University of Ottawa, Ottawa.

Schlosberg, David. 1999. Environmental Justice and the New Pluralism. Oxford: Oxford University Press.

Schlosberg, David. 2007. Defining Environmental Justice. Oxford: Oxford University Press. 
Vanderheiden, Steven. 2008. Atmospheric Justice: A Political Theory of Climate Change. New York: Oxford University Press.

Vanderheiden, Steven. 2011. 'Globalising Responsibility for Climate Change', Ethics and International Affairs 25(1): 65-84.

Voigt, Christine. 2008. 'State Responsibility for Climate Change Damages', Nordic Journal of International Law 77: 1-22.

Young, Iris Marion. 2006. 'Responsibility and Global Justice: A Social Connection Model', Social Philosophy and Policy 23(1): 102-130.

Young, Iris Marion. 2011. Responsibility for Justice. Oxford: Oxford University Press.

i Iris Marion Young died in August 2006, before completing the final revisions to her book. The final editing was completed by her husband, David Alexander.

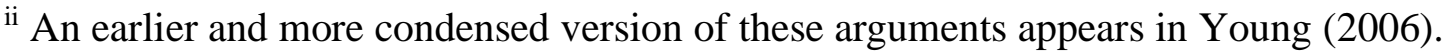


iii For example, she accepts that corporations can be held liable for damages for profiting from slavery in the past, since corporations are fictitious persons under the law and can 'live' well beyond the life of an ordinary person $(2011,175-176)$. 


\section{University Library}

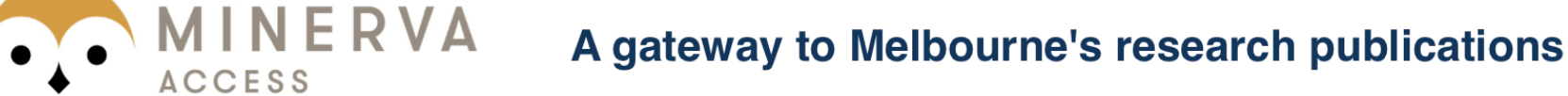

Minerva Access is the Institutional Repository of The University of Melbourne

Author/s:

ECKERSLEY, R

Title:

Responsibility for Climate Change as a Structural Injustice

Date:

2016-01-07

Citation:

ECKERSLEY, R. (2016). Responsibility for Climate Change as a Structural Injustice.

Gabrielson, T (Ed.). Hall, C (Ed.). Meyer, J (Ed.). Schlosberg, D (Ed.). Oxford Handbook of Environmental Political Theory, Oxford Handbook of Environmental Political Theory, (1), pp.1-17. Oxford University Press.

Persistent Link:

http://hdl.handle.net/11343/261042 